\title{
Virginia Tech's Innovative College Librarian Program
}

\section{Nancy H. Seamans and Paul Metz}

\begin{abstract}
In 1994, Virginia Polytechnic Institute and State University (Virginia Tech) Libraries founded a College Librarian Program. Begun with four librarians serving four colleges, it has since grown to include eleven librarians providing comprehensive library services to the six of Virginia Tech's eight colleges not served by branch libraries. Other authors have described the early history of the program or outlined some of its specific elements. ${ }^{1}$ By reviewing how the program came to be, by analyzing the choice points it presents, especially from an administrative perspective, and by discussing its benefits and costs from a university point of view, the authors hope to illuminate an exciting and potentially beneficial approach that other large institutions might seek to adapt to their own missions.
\end{abstract}

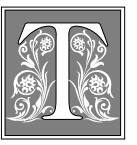

he Virginia Tech Libraries support a public university of approximately 26,000 students and 2,000 faculty members. As a land-grant institution, the university has a significant outreach mission. The University Libraries at Virginia Tech are largely centralized, consisting of one main library building and three significantly smaller branch libraries. Two of the branch libraries serve two colleges, the College of Architecture and Urban Studies and the College of Veterinary Medicine.

The centralized structure of the Virginia Tech Libraries has benefited the libraries by making it possible to run a large operation with limited staff and has benefited users by making it easy to work in interdisciplinary fields. However, the costs of centralization have always included a physical and psychological re- moteness of the library from the daily life of most faculty and serious students. The College Librarian Program was founded in large measure to overcome this distance and to more closely integrate the libraries and the use of library resources into daily academic work.

In addition to this goal, which might have been stated in any decade, several realities of the early 1990s were particularly auspicious for launching the program. These included:

- the long-awaited opportunity to access enough of the libraries' resources from remote locations to make it realistic to expect that, with sufficient support, users could do productive literature-dependent work from their offices;

- a strong push from the university administration for collaboration among units;

Nancy H. Seamans is Director of Instruction at the University Libraries of Virginia Tech; e-mail: nseamans@vt.edu. Paul Metz is the Libraries' Director of Collection Management and College-Based Services; e-mail: pmetz@vt.edu. 
- an urgent sense that point-of-need assistance would be required by users still struggling to make personal computing part of their daily work.

The College Librarian Program was founded with the strong support of Earving Blythe, vice president for information systems, to whom the libraries reported at the time. Conversations in early 1994 between Blythe and Joanne Eustis, interim director of the university libraries, revealed a shared desire to improve the libraries' status on campus through some kind of imaginative program that would connect the library to the colleges. Originally conceived as a team approach that would address both the information and the technology needs of faculty and students, the program's original sponsors were personnel from the university libraries, Virginia Tech's Educational Technologies Department, and its Communications Network Services unit. ${ }^{2}$

\section{The costs of centralization have always included a physical and psychological remoteness of the library from the daily life of most faculty and serious students.}

The College Librarian Program was designed to include functions of the Computing Center that were taxed far beyond its capabilities by the questions of first-time computer users struggling to cope in an era predating today's standardization and accompanying ease of use. The hope that librarians could provide decentralized technical support and so reduce the consulting burden of the Computing Center was a major factor in the program's initiation. The university's goals to incorporate computing in classroom teaching and other means of instructional delivery made it especially urgent that increased support be made available.

The program was officially announced in October 1994. In an article in the campus newspaper, Dana Sally of the university libraries' Reference Department indicated that "in response to academic restructuring mandates... information pro- fessionals [would be placed] in closer proximity to the largest group of information users on campus: the faculty, staff and students of the university's colleges." 3

Although the library had long assigned departments to individual librarians and asked the departments to appoint faculty liaisons to the library, the previous model was library-centric. The new program was designed to become user- and college-centric by taking the services out of the library and placing them into the colleges.

The original four college librarians were drawn from the ranks of the Reference Department. As the program was designed, the librarians were placed in offices within their colleges with the understanding that 75 percent of their time would be dedicated to serving their collegiate clientele. With no new funds available, the program was developed completely through reallocation of existing resources. It also was made clear to all from both the colleges and the libraries that there was to be no investment in distributed print collections or new branch libraries. Instead, any new collections dollars were to be focused on electronic resources that would be available to all.

Certainly the expanding availability of electronic resources was a driving factor as the program was developed. But another factor was Virginia Tech's commitment to creating a wired campus in a wired community. At the same time that the program was developing, Blacksburg was positioning itself for international recognition as one of the first "electronic villages," with Internet access being readily available not only on campus, but also throughout the community.

College librarians were intended to complement the new, but confusing, richness of digital resources by putting a personal face on the impersonal and increasingly huge body of information that was available electronically. An early phrase associated with the program was that it would combine the salutary effects of "high tech and high touch." 
The 1994-1995 annual report for the new program indicated not only that the building of interpersonal ties was a critical goal, but also that it was being attained. In the report, the college librarians emphasized growth in both the quantity and the quality of their interactions with the teaching faculty. One librarian reported that being in the college had "enhanced my relations with students and faculty, allowing me to understand more fully their mission and culture." All wrote of getting to know their faculty members better, of attending faculty meetings and being named to committees in their colleges, and of having a better understanding of their faculty members' and graduate students' research needs. They all mentioned supporting faculty members needing assistance with computers, computer resources, and connectivity. Moreover, they reported the creation of subject-specific World Wide Web resource pages and talked about assisting with everything from e-mail to course development. During the year, all had presented both classes and informal sessions on library resources and the best uses of technology. ${ }^{4}$

In the 1995-1996 academic year, two additional college librarians were added to the program at the request of colleges not yet served by the program. In addition, because of the large constituency served by the single college librarian for the College of Arts and Sciences, a second position was added. This distribution of resources, together with the existing branch libraries, ensured that each of the eight colleges was receiving the benefits of one or more assigned librarians. The emphasis during this year appears to have begun to shift away from technology support and to focus on support for curriculum development and instruction. However, the college librarians were still taking leadership roles in the technology arena, with two of them participating in the development of Web sites for their colleges.

The program has continued to grow in recent years. Excluding the two branch librarians, there are now eleven college librarians (four for the College of Arts and Sciences alone). The college librarians are justifiably proud of their unique role at the university, where their primary responsibility is not to the library but, rather, to the college they serve. They have created virtual collections via a wide variety of departmental Web pages and have provided a mechanism for taking the library to its communities with minimal expense to the library.

Moreover, the college librarians have assumed responsibility for the majority of the instruction offered by the university libraries. Partly in recognition of this increasing instructional role, and as the result of a librarywide reorganization, the college librarians were designated as the core members of a new Instruction Department created in 1999. With this reorganization, the college librarians now report jointly to the authors who are the director of instruction and the director of collection management and college-based services.

\section{The Multiple Roles of the College Librarian}

The critical issue to be resolved in establishing any program for satellite librarians is to decide which of the many functions that a librarian might pursue should be filled by the incumbents. As the authors reflect on the history of the program at Virginia Tech, the centrality of this question becomes increasingly apparent.

Ideally, if the college librarian is to be presented as someone who can handle almost all of a department's library needs and can correctly refer the exceptional cases, each college librarian will play every role the public associates with library service. But as roles are added, not only is a potentially unrealistic standard for versatility and breadth of talent and knowledge among the college librarians set, but training burdens and complicated relations with specialized areas within the library are added. Ultimately, one also starts to require that either supervisors themselves be polymaths, capable of providing policy direction in all areas, or the number of supervisors be multiplied. 
The potential roles a college librarian might play include those of:

- reference librarian;

- instructor in library and information literacy skills;

- builder of library collections;

- Web master for relevant library resources;

- colleague in the life of the college;

- provider of technical support (PC/ Mac and software guru).

Considering each of these roles in turn is probably the best way to tease out both the benefits and the difficulties that arise from a College Librarian Program.

It is easier to sell this approach when the librarian is a familiar coresident of the academic buildings.

\section{Reference Librarian}

Although library turnstile and circulation counts are holding more or less steady and Web page hits are growing madly, reference desk interactions are down in nearly all academic libraries. ${ }^{5}$ If this is because library users have become more sophisticated in defining research questions, identifying appropriate resources, and evaluating the information they obtain, this trend might be celebrated. But the considerable evidence of user naiveté about the Internet is one of the key arguments for a program that gives students and other users access to the services formerly sought at the reference desk.

As Virginia Tech's program has taken hold and as more college librarians have started to spend much of their time in the college offices, the contact between them and their clientele has become quite extensive. College librarians are often asked by their clientele to help with literature reviews, to check citations, to provide facts, to make referrals, or to provide other forms of reference service. It would be inaccurate to label all contacts between the college librarians and their clientele as reference transactions. Indeed, the blurring of the various professional and social kinds of interactions between college librarians and their clientele that makes it impossible to categorize each contact precisely is a sign of health. But in a typical year, the college librarians now will have more than 1,000 interactions they would categorize as largely of a reference nature, meet or consult with more than 1,500 individuals or groups, and reply to thousands of e-mails.

\section{Instructor}

The same technological forces that have led to a drop-off in reference desk activity-the movement of library resources to Web-based accessibility and the emergence of competing information resources of a wide range of quality and credibility-make it imperative that academic libraries redouble their instructional efforts. The goal at Virginia Tech is to equip students to use library resources efficiently, but to do so as a part of a much larger program devoted to instilling lifelong skills in information literacy. Although our reach has often exceeded our grasp, we strive first to give each new student the basics, chiefly through first-year English and Communication Studies classes, and then to identify the appropriate upper-level courses in which to partner with faculty in imparting discipline-specific information skills.

Virginia Tech's librarian for first-year and outreach programs coordinates its freshman program instructional efforts. These efforts do not generally require much involvement on the part of the college librarians, although some of them teach class sessions during peak times. (Several college librarians are serving on a team that is involved in developing a comprehensive program for first-year students, and more will be involved in building on this program to develop a cumulating library instructional program for the university.) However, the more specialized task of teaching business students how to use Dow-Jones or the Wharton Research Data Service or of acquainting engineering students with Compendex, INSPEC, and online standards relies heavily on the college librarians. 
The librarians are working with the academic departments to identify appropriate courses that most students will take early in the major and to establish partnerships between the college librarians and the instructors. It is easier to sell this approach when the librarian is a familiar coresident of the academic buildings. When a student who has had a librarian's class passes the librarian in the hall the next day or sees him or her in an office in the college, there is an obvious opportunity to reinforce the lesson or to extend it to meet a specialized information need.

\section{Bibliographer}

Most of the library information and materials budget is in fund lines controlled by the branch librarians or the college librarians, who shoulder the full range of collection development responsibilities. Each has a "firm order" budget line for books and other one-time acquisitions in each disciplinary fund she or he controls, and each is responsible for dialogue with faculty and other users about resources, including those being examined on trial. Under a relatively short-lived reorganization in the mid-1990s, collection development was vested in a separate department. This scheme was abandoned, chiefly because college librarians reported that the surrender of collection development responsibilities had reduced their credibility and interaction with their teaching faculty.

\section{Web Master}

Although the breadth of the college librarians' duties makes them generalists in a functional sense, they build considerable specialized subject competence through their focus on the needs of specialized clientele. The Web page for the university libraries at Virginia Tech includes "subject resource pages," which link not only to the relevant library resources for the discipline, but also to pedagogic resources, professional associations, and related Virginia Tech and discipline sites. Each college or branch librarian maintains the subject pages for his or her discipline.
The libraries offer technical assistance to those college librarians who want help with their Web pages, but all the college librarians are exclusively responsible for content.

\section{Colleague}

The role of faculty colleague-of a junior variety in most, but not all, contexts-has come as a largely unanticipated by-product of the college librarians' presence as collaborators and neighbors with the teaching faculty. It is not uncommon now for college librarians to attend the regular meetings of department heads with their academic deans, to travel with other faculty to workshops or national meetings, or to serve on faculty search committees. A few have participated as coinvestigators on grants, especially for projects that include an element of collection building.

\section{Technician}

It is paradoxical that although the notion that librarians could serve as mobile computer and software support staff was very much on the minds of the information systems administrators who initially proposed the program, technical support is the only potential role not formally played by Virginia Tech's college librarians (who are nonetheless happy to help a faculty member install a program or identify a virus).

For several months after the idea first surfaced, the libraries successfully resisted the concept on the grounds that librarians were not well trained on hardware and software support and that few true library resources were yet available for remote use. But by the time the College Librarian Program was implemented, the university had launched its award-winning Faculty Development Institute giving all faculty new computers and training on their use. Computing had also become easier and self-made experts had emerged in every department. It was therefore possible to omit any formal expectation that librarians would provide significant technical support. 


\section{Various Approaches and Emphases among the College Librarians}

One of the blessings, but also one of the challenges, of the college librarian role is that each incumbent must define it in his or her own way. College librarians bring to their task a considerable range of approaches, the variety of which seems to be about equally an outcome of their individual skills, abilities, and interests and the dissimilar needs and cultures of their clientele.

The college librarian for agriculture and the college librarian for business spend most of their time in their colleges. Apart from her extensive campus contacts, the college librarian for agriculture travels throughout the state to work with extension agents and visits the Commonwealth's experiment stations. The needs of her far-flung constituents also have made her a forceful and informed advocate for improved document delivery mechanisms within the library. The college librarian for business emphasizes on-site assistance and training with the highly specialized corporate and financial databases important to her constituency, although she continues to provide general reference desk assistance and holds office hours in her library office as well as her college office.

At the other pole from them in terms of where they can be found at any time are the two college librarians for engineering, who have not found it productive to spend time in their college. Both have given up their college offices, partly because their departments are widely scattered, but mainly because the culture of engineers encourages reliance on e-mail and phone and on just-in-time, point-of-need delivery of information. (Virginia Tech engineers do not just drop in to chat!) Responding to these realities, the college engineering faculty concentrate on collection development, on building highly informative and efficient Web pages, on providing instruction for engineering students, and on extensive one-on-one consulting from their offices adjacent to the $\mathrm{T}$ call numbers in the main library.
Most of the other college librarians fall somewhere in between these poles in terms of where they spend their time and the roles they emphasize.

\section{Behind the Lines: Structures and Resources Required to Support the Program}

Having elected to empower the college librarians with virtually all the roles that could be vested in their positions, the Virginia Tech University Libraries also have maximized the supervisory burden, the complexity, and the need for support from behind the front lines required for programmatic success. These challenges have been by no means insuperable, but they have required careful planning and continuous follow-up.

As previously indicated, the college librarians co-report to the director of instruction and the director of collection management and college-based services, who communicate with one another continuously to coordinate priorities and workloads. These supervisors must keep a close eye on the relationship of the college librarians to the overall library management of the functions they serve. These relationships are again best considered in terms of the college librarians' roles.

\section{Reference}

The duties of the reference role posed no particular challenge to Virginia Tech's first college librarians, who were transfers from the Reference Department and were very familiar with the entire range of reference services and resources. As these librarians have been replaced with new hires, most of whom have been new to the university as well as to the program, new college librarians have been required to go through the training program offered to all reference staff and to work the main reference desk at least four hours weekly throughout their first year at Virgina Tech. Several have chosen to work the desk beyond that, either continuously or for an occasional semester, so as to maintain their skills and knowledge. 
The college librarians who work the reference desk are on e-mail lists through which they receive updates on new resources or policies. Coordination also is sought through monthly joint meetings of all staff in the Reference, Instruction, and Collection Management departments.

\section{Instruction}

The most recent reorganization of the libraries, in 1999, established the Instruction Department. The college librarians play a central role in planning and coordinating all aspects of the instructional program other than those for first-year students. During the first year of the Instruction Department, the college librarians were instrumental in developing evaluation tools that were used to evaluate approximately 80 percent of the instruction sessions offered by university libraries personnel. In 2001-2002, they took a lead role in the redesign of the departmental Web site and in 2002-2003 will collaborate with faculty on the use of Webbased Information Skills Modules that are being developed by a team led by the college librarian for the College of Agriculture and Life Sciences.

Although information literacy was a component of the early years of the College Librarian Program, in the past two years it has become a key component of the Instruction Department's mission. Part of the mission statement, approved in 1999 by all members of the department, states: "We will collaborate with members of the University Community in developing instructional programs that will help them to identify, locate, and evaluate information, and will support them in their lifelong learning and teaching endeavors."

A significant amount of instruction was taking place prior to the creation of the department, but instruction session and student numbers have shown a dramatic and steady increase in the two years since the department was created. During the 1998-1999 academic year, the year before the department was established, 391 sessions were presented to 7,147 students. In 2000-2001, the number increased to 585 sessions with 11,215 students contacted.

\section{Collection Management}

Collection development has had the same department head for many years, as a result of which policy goals, budgetary structures, and detailed procedures were in place and widely understood before the

The more the college librarians take to their role, the less visible their accomplishments sometimes are from the library.

program was launched. All of the original college librarians already had collection development responsibilities when they took on their new duties, although assignments had to be adjusted to reflect the new division of labor according to college lines. (Earlier, some otherwiselogical combinations such as education, psychology, and human development, at one time spread across three colleges, had defined individuals' assignments.)

Because among them the college librarians carry the majority of the materials budget, their efforts are central to the libraries' success in this domain. But in their collection development role, they are treated simply as bibliographers and attend monthly meetings with the department head, the branch librarians, and the handful of individuals responsible for selection in such specialized areas as military science, law, and medicine. Major projects such as serials cancellations or minor ones such as the updating of policies or advising the department head about the approval plan are assigned equally to all bibliographers. Groups of bibliographers assemble at least twice a year to consider new serials subscriptions.

\section{Web Mastery}

Overall responsibility for the libraries' Web presence resides with a librarian Web master within the Reference Department. He is guided by a steering committee on which college librarians are well represented. The committee has provided loose guidelines that allow college librarians and others to construct subject pages that 
have a consistent format and "look" but allow great flexibility for discipline-specific kinds of information.

\section{Challenges Posed by a College Librarian Program}

The College Librarian Program at Virginia Tech has been a remarkable success and can serve as a model for transferability to other institutions. Nonetheless, there are potential disadvantages, the omission of which would leave an unbalanced picture. These include:

- the inconvenience of maintaining and equipping two offices, even if both are shared with others;

- the continuous need for coordination between supervisors and functions;

- interpersonal tensions resulting from the perception that college librarians are unusually free to set their own schedules, are unaccountable outside their department even though their work affects other units, or are advantaged by being in unusually visible positions;

- the potential for conflicting loyalties, with the attendant risk that college librarians may make the central administration look bad;

- difficulty in accounting for the time of college librarians or measuring their accomplishments in valid and reliable ways;

- the need to hire people who are self-starters and can work independently balanced against the need to provide some way of accounting for the use of time by the college librarians.

Among the remedies for these risks, the most effective are awareness, effort, and continuous dialogue.

Evaluation is not an easy task when the professionals being evaluated have great freedom and are encouraged to take initiative. The authors have specifically addressed the difficulty of accounting and evaluation by devising a standardized, Web-based means for reporting all outreach activities of more than fifteen minutes' duration. These are categorized by type (class, tour, presentation, or other). The time invested, the place, the affiliation and level of the clientele, and the number of people contacted are all recorded. The authors also have found that the more the college librarians take to their role, the less visible their accomplishments sometimes are from the library. Therefore, in the near future the authors will ask the academic deans to solicit and organize faculty perceptions and comments to be used as an important element in the annual evaluation of the college librarians.

\section{Benefits of a College Librarian Program}

In the early 1990s, Virginia Tech had a few advantages that helped make it possible to establish a College Librarian Program. These included faculty status for librarians, a centralized library structure, a history of matching librarians to academic units and of decentralized collection development, and a strong technological infrastructure. Although these advantages may explain Virginia Tech's early start, none of them is so fundamental to the program that it might not work equally well in other settings.

So, given the challenges described in the previous section, should all large academic libraries disburse a majority of their public services staff across their campuses? Although the authors can only definitively answer for Virginia Tech, they would enthusiastically affirm that the benefits to their users, as well as to the libraries, have greatly outweighed the costs and suggest that there is a strong case to be made for transferability to other campuses. A minimal listing of the advantages includes:

- Distributed public services encounter users where they spend their time, making help available where and when it is needed, whereas traditional services wait for users in a location they do not often care to visit.

- Librarians who split their time between the library and the constituents' sites acquire a much more detailed and grounded understanding of campus needs.

- Distributed public services facilitate a shift away from distributed physi- 
cal collections, making it possible for libraries to abandon inefficient branch locations.

- Physical propinquity facilitates formal and informal partnerships with faculty, leading not only to more comprehensive and relevant team-teaching of information literacy concepts and skills, but also to a transformation of librarians' participation in campus culture and governance.

Readers may have observed that other bases, such as the distribution of departments across campus buildings, might be substituted for college lines as the basis for the division of labor among distributed or college librarians. Such a means of making assignments would have a surface logic in several ways, including a more finely graded distribution of resources. (Indeed, the authors have sometimes felt that one or another college might need an additional half of a college librarian and felt some frustration that college librarians come in irreducible human quanta!)

It would be the authors' advice to resist this temptation and to insist on colleges as the unit of distribution because only this approach ensures the backing of the academic deans. Although there has been variation among Virginia Tech's deans in the resources they either could or did give the program, even the less enthusiastic deans have supported the program fully.

The authors view the College Librarian Program as an exemplar of the kinds of barrier-disregarding, technology-leveraging, connection-making aggressive innovation that will characterize the top-tier institutions in the coming decades of change and transformation in higher education. To evaluate the program from the libraries' point of view would miss the point: surely the libraries' clientele must be granted that podium. The authors believe that the strongest evidence of the success of Virginia Tech's College Librarian Program has come from the deans. They have given office space, meeting time, and direct financial support for travel. They have spoken in favor of the program in both administrative and shared governance settings. Perhaps most tellingly, each has made certain that his or her college gets and keeps its fair share from the program.

\section{Notes}

1. Jane E. Schillie, Virginia E. Young, and Susan A. Ariew, "Outreach through the College Librarian Program at Virginia Tech," Reference Librarian 71 (2000): 71-78; Ladd Brown, Molly Brennan-Cox, and Nancy H. Seamans, "College Librarians: Partners in Acquisitions and Serials Management (Liaison Program at Virginia Tech)," Against the Grain 12 (Nov. 2000): 28-30; John K. Stemmer and John W. Tombarge, "Building a Virtual Branch. CLIO Program: Collegiate Librarian and Information Officer Placed in Various Colleges at Virginia Tech," College E Research Libraries News 58 (Apr. 1997): 244-48; Linda Maddux, "The CLIO Experience: Collegiate Librarian/ Information Officer for the College of Agriculture and Life Sciences, Virginia Tech," Virginia Librarian 41 (July / Aug./Sept. 1995): 14-15; Joanne Eustis, Linda Maddux, and Dana M. Sally, “Adapting Information Services to New Realities: The College Librarian/Information Officer Program at Virginia Tech. Placing Librarians in Individual Colleges of Virginia Tech to Provide Customized On-site Services," Virginia Librarian 41 (July/Aug./Sept. 1995): 13-16; Richard Raspa and Dane Ward, The Collaborative Imperative: Librarians and Faculty Working Together in the Information Universe (Chicago: Association of College and Research Libraries, 2000).

2. Telephone interview with Joanne Eustis, October 5, 2001.

3. Dana Sally, October 6, 1994, Virginia Tech Spectrum.

4. Annual Report, College Librarian Program, Virginia Tech University Libraries, 1995.

5. Scott Carlson, "The Deserted Library: As Students Work Online, Reading Rooms Empty Out-Leading Some Campuses to Add Starbucks," Chronicle of Higher Education XLVIII (Nov. 16, 2001): A35-A38.

6. Mission Statement, Instruction Department, Virginia Tech University Libraries, 1999. 